\title{
HIV-1 Tat mimetic of VEGF correlates with increased microvessels density in AIDS-related diffuse large B-cell and Burkitt lymphomas
}

\author{
J. Nyagol • G. De Falco • S. Lazzi • A. Luzzi • \\ G. Cerino $\cdot$ S. Shaheen $\cdot$ N. Palummo $\cdot$ C. Bellan • \\ D. Spina $\cdot$ L. Leoncini
}

Received: 12 December 2007 / Accepted: 19 February 2008/Published online: 16 April 2008

(C) Springer-Verlag 2008

\begin{abstract}
Angiogenic switch marks the beginning of tumor's strategy to acquire independent blood supply. In some subtypes of non-Hodgkin's lymphomas, higher local vascular endothelial growth factor (VEGF) expression correlates with increased microvessel density. However, this local VEGF expression is higher only in tumors with elevated expression of the receptors of the growth factor, suggesting an autocrine growth-promoting feedback loop. Several studies have indicated that VEGF receptors are also targeted by Tat protein from the HIV-1-infected cells. Given the similarity of the basic region of Tat to the angiogenic factors (basic fibroblast growth factor, VEGF), Tat mimics these proteins and binds to their receptors. We evaluated the role of HIV-1 Tat in regulating the level of VEGF expression and microvessel density in the AIDS-related diffuse large B-cell (DLBCL) and Burkitt lymphomas (BL). By luciferase assay, we showed that VEGF promoter activity was downregulated in vitro in cells transfected with Tat. Reduced VEGF protein expression in primary HIV-1 positive BL and DLBCL, compared to the negative cases, supported the findings of promoter downregulation from the cell lines. Microvascular density assessed by CD34 expression was, however, higher in HIV-1 positive than in HIV-1 negative tumors. These results suggest that
\end{abstract}

\footnotetext{
J. Nyagol · G. De Falco · S. Lazzi • A. Luzzi • G. Cerino ·

N. Palummo $\cdot$ C. Bellan $\cdot$ D. Spina $\cdot$ L. Leoncini $(\square)$

Department of Human Pathology and Oncology,

University of Siena,

Via Delle Scotte 6,

53100 Siena, Italy

e-mail: leoncinil@unisi.it

S. Shaheen

Department of Pathology, Aga Khan University Hospital, Nairobi, Kenya
}

Tat has a wider angiogenic role, besides the regulation of VEGF expression. Thus, targeting Tat protein itself and stabilizing transient silencing of VEGF expression or use of monoclonal antibodies against their receptors in the AIDSassociated tumors will open a window for future explorable pathways in the management of angiogenic phenotypes in the AIDS-associated non-Hodgkin's lymphomas.

Keywords HIV-1 Tat · Microvessel density . Diffuse large B-cell · Burkitt lymphoma

\section{Introduction}

Under normal circumstances, angiogenesis is restricted to the sites of vessel injury as well as de novo formation of the embryonic circulatory system (vasculogenesis). However, pathological forms of increased angiogenesis have also been documented for degenerative eye disease, atherosclerosis, and during tumor progression [1].

Angiogenesis is regulated by a plethora of the growthand differentiation-promoting factors, which include the release of angiogenic factors locally by cells under hypoxic conditions [2-4]. Vascular endothelial growth factor (VEGF), a dimeric polypeptide growth factor related to the platelet-derived growth factor, is among the primary factors modulating the behavior of the endothelial cells in this process. An increase in VEGF expression in tumors has been reported in solid and hematological malignancies, being associated with increased angiogenesis, metastasis, and poor prognosis [5]. The functions of VEGF are only effective upon binding to either of the two isoforms of tyrosine kinase receptors, that is, vascular endothelial growth factor receptor (VEGFR)-1 (also called fms-like 
tyrosine kinase (Flt-1)) and VEGFR-2 (kinase domain receptor (Flk-1/KDR)) [6, 7].

In experimental models of AIDS-associated angioproliferative Kaposi's sarcoma (KS) cells, Tat protein of HIV-1 has been widely implicated in the increased angiogenesis, and many studies have also indicated that VEGFRs are targeted by the protein [8]. The basic region of Tat, rich in arginine and lysine amino acids, is a putative sulfate heparin-binding domain, which is similar to the sequences of heparin-binding angiogenic factors (basic fibroblast growth factor, VEGF) [9]. In particular, it has been demonstrated that Tat is able to bind to the VEGFR-2/ KDR with high affinity and to determine the activation of its downstream signaling through its phosphorylation, similarly to the proper ligand, VEGF [10]. Furthermore, family of heterodimeric receptors (integrins), which promote endothelial cells' adhesion to extracellular components and the VEGFR-2/KDR, have been identified as the two types of signaling receptors activated by extracellular Tat. Binding of Tat to this receptor has been shown to be blocked by VEGFR inhibitors, indicating that binding occurs at the same sites as for the authentic VEGF [11].

Therefore, Tat is characterized as a functional peptide mimetic for VEGF, a concept that is also tentatively supported by clinical data [12,13]. Notwithstanding, studies on the roles of Tat protein in the oncogenic and angiogenic phenotypes of non-Hodgkin's lymphomas are quite limited. Since the mechanisms by which tumor cells switch to the angiogenic phenotype involve a balance between angiogenic stimulators and angiogenic inhibitors, we hypothesized that Tat protein may modulate VEGF expression, which in turn increases angiogenesis. As B-cells are not a target for HIV infection, but a soluble form of Tat may be released from infected cells and taken up by uninfected ones, in a previous study, we have demonstrated that AIDSrelated lymphomas are positively immunostained with an anti-Tat antibody [14], thus suggesting that Tat itself may contribute to an AIDS-related lymphomagenesis.

In the present study, we aimed at investigating whether Tat may have a role in modulating the activity of the VEGF promoter, as well as in increasing angiogenic potentials, in AIDS-related Burkitt lymphomas (BL), and in diffuse large B-cell lymphomas (DLBCL).

\section{Materials and methods}

Study cases

A total of twenty-nine, $10 \%$ formalin-fixed paraffinembedded tissue blocks of DLBCL and BL were retrieved at random from the archives of the Department of Human Pathology and Oncology, University of Siena, Italy and the
Department of Pathology of the Aga Khan Hospital, Kenya. Informed consent to carry out the study was granted by the institutions' ethical review committee and it was in accordance with the declaration of Helsinki. Sections made from these paraffin embedded tissue blocks were stained with hematoxylin and eosin to confirm the previous diagnoses.

Sections made from the tissue blocks were stained with hematoxylin/eosin and immunophenotyping done to confirm the previous diagnoses. HIV-1 status was confirmed by the polymerase chain reaction (PCR) analyses, and the study cases were then classified as shown in Table 1. The presence of Epstein-Barr virus (EBV) was assessed by in situ hybridization for EBV-encoded RNA (EBER) using a 30-base oligonucleotide probe complementary to a portion of the EBV-encoded small nuclear RNA (EBERl) gene, as previously described [14].

\section{Cell lines}

The human 293 cell line and the Burkitt lymphoma-derived cell line Raji were obtained from the American Type Culture Collection (Rockville, MD, USA). Two hundred ninetythree cells were cultured in Dulbecco's modified eagle's medium supplemented with $10 \%$ fetal bovine serum (FBS), $1 \%$ L-glutamine, and $1 \%$ penicillin/streptomycin, in a humidified atmosphere containing $5 \% \mathrm{CO}_{2}$, at $37^{\circ} \mathrm{C}$. Raji cells were grown in RPMI medium supplemented with $10 \%$ FBS, $1 \%$ L-glutamine, and $1 \%$ penicillin/streptomycin, in a humidified atmosphere containing $5 \% \mathrm{CO}_{2}$, at $37^{\circ} \mathrm{C}$.

\section{Plasmids}

Both the artificial VEGFR promoter, linked to a luciferase reporter gene, and the pcDNA3-Tat vector have been previously described [15].

\section{Transfections}

The 293 cells represent a useful model, resulting in high transfection efficiencies, to achieve ectopic expressions of targeted gene. The in vitro experiments using VEGF promoter were therefore performed in the 293 cells and then confirmed in the Raji cells. The 293 cells were transfected with the calcium phosphate kit (Invitrogen, CA, USA), whereas the Raji cells were transfected by the nucleofection using an AMAXA apparatus, with solution $\mathrm{T}$ and program T16 (Amaxa, Germany). Forty-eight hours after the transfections, cells were harvested for luciferase assay.

\section{Luciferase assay}

For luciferase assay, two micrograms of each plasmid were transfected. Cells were harvested $48 \mathrm{~h}$ from the 
Table 1 Classification of study cases

\begin{tabular}{lcccr}
\hline $\begin{array}{l}\text { Lymphoma type } \\
\text { (number) }\end{array}$ & $\begin{array}{l}\text { Age range } \\
\text { (median) }\end{array}$ & $\begin{array}{l}\text { Sex } \\
\text { (female/male) }\end{array}$ & $\begin{array}{l}\text { Site } \\
\text { (nodal/extranodal) }\end{array}$ & EBV+/total \\
\hline BL (16) & $4 / 56(17)$ & $4 / 12$ & $6 / 10$ & $14 / 16$ \\
DLBCL (13) & $27 / 45(36)$ & $3 / 10$ & $6 / 7$ & $6 / 13$ \\
\hline
\end{tabular}

transfection and subjected to luciferase assay. Luciferase assay was performed in triplicate, as previously described [16]. Luciferase activity was assayed using a dual luciferase assay kit according to the manufacturer's instructions (Promega, Madison, WI, USA) and measured using a luminometer (Turner, Promega, Madison, WI, USA).

Immunohistochemical staining

Immunohistochemistry was performed on sections from primary tumors by the immunoperoxidase (for CD34) and alkaline-anti-alkaline phosphatase (for VEGF) techniques, following preheat retrieval of antigen epitopes. The technique of immunohistochemistry has been previously described [17]. The clones of monoclonal antibodies and concentrations used are shown in Table 2. Unlike antiCD31, the antibody CD34 does not cross-react with lymphoid cells, and better quality of staining than with anti-factor VIII was obtained.

\section{Evaluation of immunostaining}

VEGF and CD34 staining were initially graded on a scale of 0 to 3 , depending on the intensity of the staining as described in Table 3 . This grading scale is a modification of the Takahashi et al. system [18].

Microvessel count and density

Microvessel density (MVD) was evaluated as previously described [19]. Briefly, CD34 stained sections underwent individual microvessel count on a grid square of $0.025 \mathrm{~mm}^{2}$, at $\times 630$ magnification in the 11 identified areas of most intense immunostains using Zeiss Axioscop 40 microscope (Carl Zeiss, Germany). MVD was defined as the mean number of microvascular profiles per $\mathrm{mm}^{2}$ from the 11 hot spots assessed in each study case. Any

Table 2 Clones of antibodies used and their source

\begin{tabular}{lll}
\hline Antibody & Clone (dilutions) & Source \\
\hline VEGF & VG1 (1:100) & DAKO (Milan, Italy) \\
CD34 & QBEnd 10 (1:100) & DAKO (Milan, Italy) \\
\hline
\end{tabular}

brown-staining endothelial cell or endothelial cell cluster clearly separated from adjacent microvessels, tumor cells, and normal cells with or without the presence of a lumen was considered as a single countable microvessel. The average of microvessel counts from the 11 hot spots for each case was used for MVD assessment. Immunostains and the vessel counts were assessed without prior knowledge of the patients' HIV-1 status by two pathologists independently, obtaining concordance of more than $98 \%$. Where discordance was noted, the two pathologists reviewed the cases simultaneously using double-headed light microscope.

\section{HIV-1 testing using PCR technique}

For HIV-1 testing, DNA was extracted and nested PCR performed as previously described [20].

\section{Statistical analyses}

Differences in mean vessel counts, mean staining, and intensity of VEGF among HIV-1 positive and HIV-1 negative cases were analyzed by the SYSTAT statistical program. Kruskal-Wallis one-way analysis was used to test the association between microvessel counts and HIV-1 status. Pearson correlation matrix was then used to test interparametric correlations, and values of $p<0.05$ were considered statistically significant.

\section{Results}

HIV-1 Tat downregulates VEGF promoter activity

We aimed at investigating whether Tat was able to modulate the activity of the VEGF promoter. Therefore,

Table 3 Immunoassay score used for both VEGF and CD34

\begin{tabular}{lll}
\hline Score & $\%$ positive cells & Intensity of the reaction \\
\hline 0 & No positive cells & No positive reaction \\
1 & $<10 \%$ positive cells & Faint color reaction \\
2 & $10-50 \%$ positive cells & Moderate color reaction \\
3 & $>50 \%$ positive cells & Intense color reaction \\
\hline
\end{tabular}


a VEGF promoter linked to a luciferase reporter gene, alone or in combination with a vector coding for Tat, was transfected in 293 and Raji cells. Luciferase assay showed that Tat protein is able to downregulate the activity of the VEGF promoter, as compared with the empty vectortransfected cells (Fig. 1a and b). The repression of VEGF promoter due to Tat binding was correlated with the low expression of VEGF in HIV-1 positive primary tumors compared to the negative cases (Fig. 2).

HIV-1 positive DLBCL and BL have different patterns of microvessel density from the negative cases

It is known that Tat is released in a soluble form by the infected cells and taken up by the uninfected ones [21]. In fact, a previous study of our group showed that AIDSassociated B-cell lymphomas were positive when immunostained with an anti-Tat antibody, thus indicating that Tat may act as an oncogenic factor [14]. In the present study, we tested primary tumor cases for the expressions of VEGF and CD34 (a specific marker for microvessel density), and a distinct pattern between the HIV-1 positive and HIV-1 negative cases was observed. In the AIDSassociated cases, low expression of VEGF, consistent with inactivated VEGF expression, was realized in both BL and DLBCL (Fig. 2). These findings were consistent with those obtained from the cell lines, in which VEGF promoter repression resulted in reduced luciferase activity. Evaluated through CD34 expression, increased MVD in HIV-1 positive tumors was observed (Fig. 3), pointing to the role that Tat plays in the increased endothelial cell proliferation and augmented vasculature. In HIV-1 positive DLBCL, statistical significant values for microvessel counts, as well as the mean number of microvessels, were realized for the minimum counts $(p=0.010)$, maximum counts $(p=0.003)$, median number of counts $(p=0.005)$, and mean $(p=0.003)$. In HIV-1 positive BL cases, minimum microvessel counts ( $p=0.042)$, maximum counts $(p=0.048)$, and median ( $p=$ $0.034)$ reached the statistical significant values, with a borderline figure for the mean $(p=0.051$; Fig. 4). This could be attributed to the other angiogenic factors as have been previously reported [22]. EBV status did not influence microvessel formation.

\section{Discussion}

Differences in VEGF expression and correspondingly higher microvessel density among the subtypes of nonHodgkin's lymphomas have been suggested to have important implications for the responsiveness of these tumors to the anti-angiogenic therapies. Both experimental and clinical data related to angiogenesis in the hemapoietic neoplasia are relatively limited. However, an increase in the expression of angiogenic factors and microvessel density has been linked to increase angiogenesis, tumor progression, and poor prognosis in both solid and hematological malignancies [22].

Tumors are known to stimulate local vascular endothelial growth factor expression and autocrine growth-promoting feedback loop during pathological angiogenesis. Besides, all members of the VEGF family stimulate endothelial cellular responses by binding to tyrosine kinase receptors (VEGFRs) on the cell surface, causing them to dimerize and become activated through transphosphorylation, although to the different sites and extents [23, 24]. Vascular endothelial growth factor, an important endothelial cell mitogen associated with increased an- a

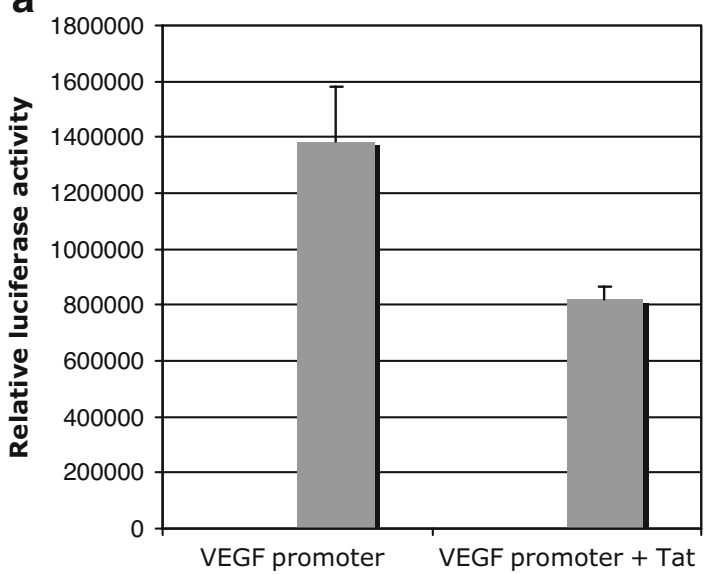

Fig. 1 Luciferase assay for VEGF promoter activity in both Tat- and empty vector-transfected 293 cell line (a) and Raji cell line (b). Ectopic expression of Tat in 293 cells is able to downregulate the b

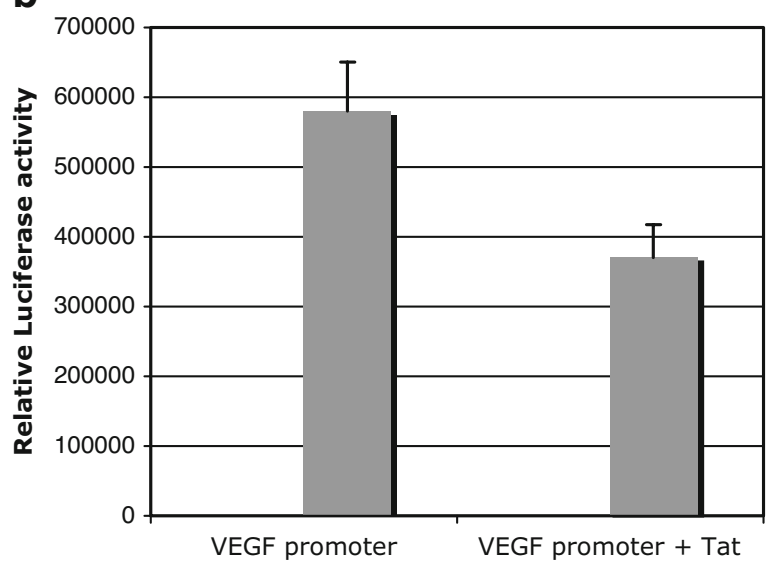

activity of a VEGF promoter linked to a luciferase reporter gene (a). These findings were confirmed in the Tat-transfected Raji cells (b) 
Fig. 2 VEGF expression in primary HIV-1 positive or negative DLBCL and BL tumors. Higher expression of VEGF was observed for HIV-1 negative $\operatorname{DLBCL}$ (a) and BL (c), as compared to the corresponding histotypes in HIV-1 negative cases (b and $\mathbf{d}$ ), respectively
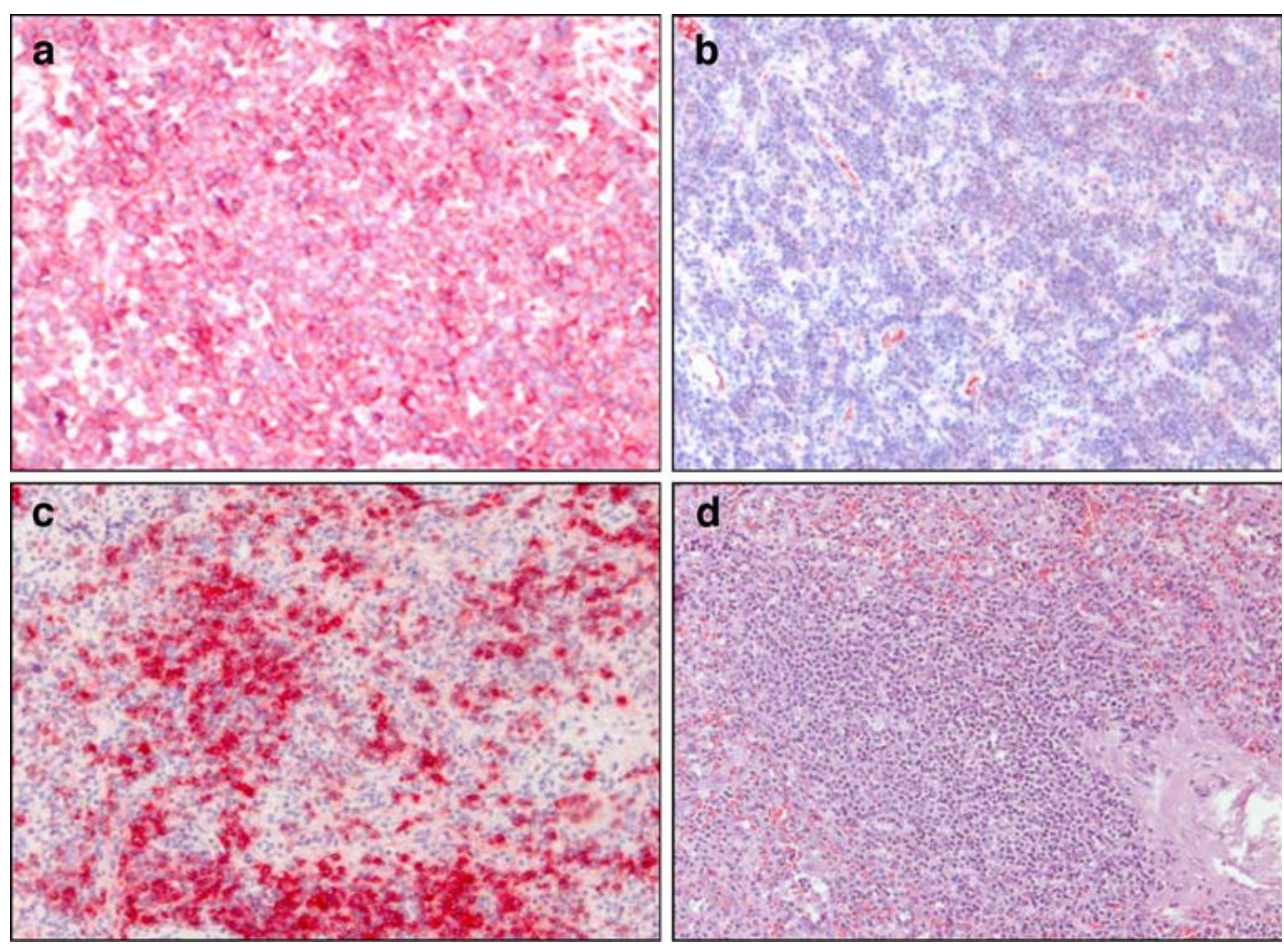

giogenesis and aggressive tumor is well-characterized in the AIDS-associated angioproliferative tumor, KS. Its stimulating effect on endothelial cells is, however, still largely dependent on the presence of specific VEGF receptors, such as the VEGFR2 (Flk-1/KDR) receptor [25-29].

Fig. 3 CD34 expression in both DLBCL and BL positive or negative for HIV-1. Irrespective of the histotype, expression of CD34 was low in HIV-1 negative DLBCL (a) and BL (c), as compared to the corresponding histotypes positive for HIV-1 (b and d), respectively
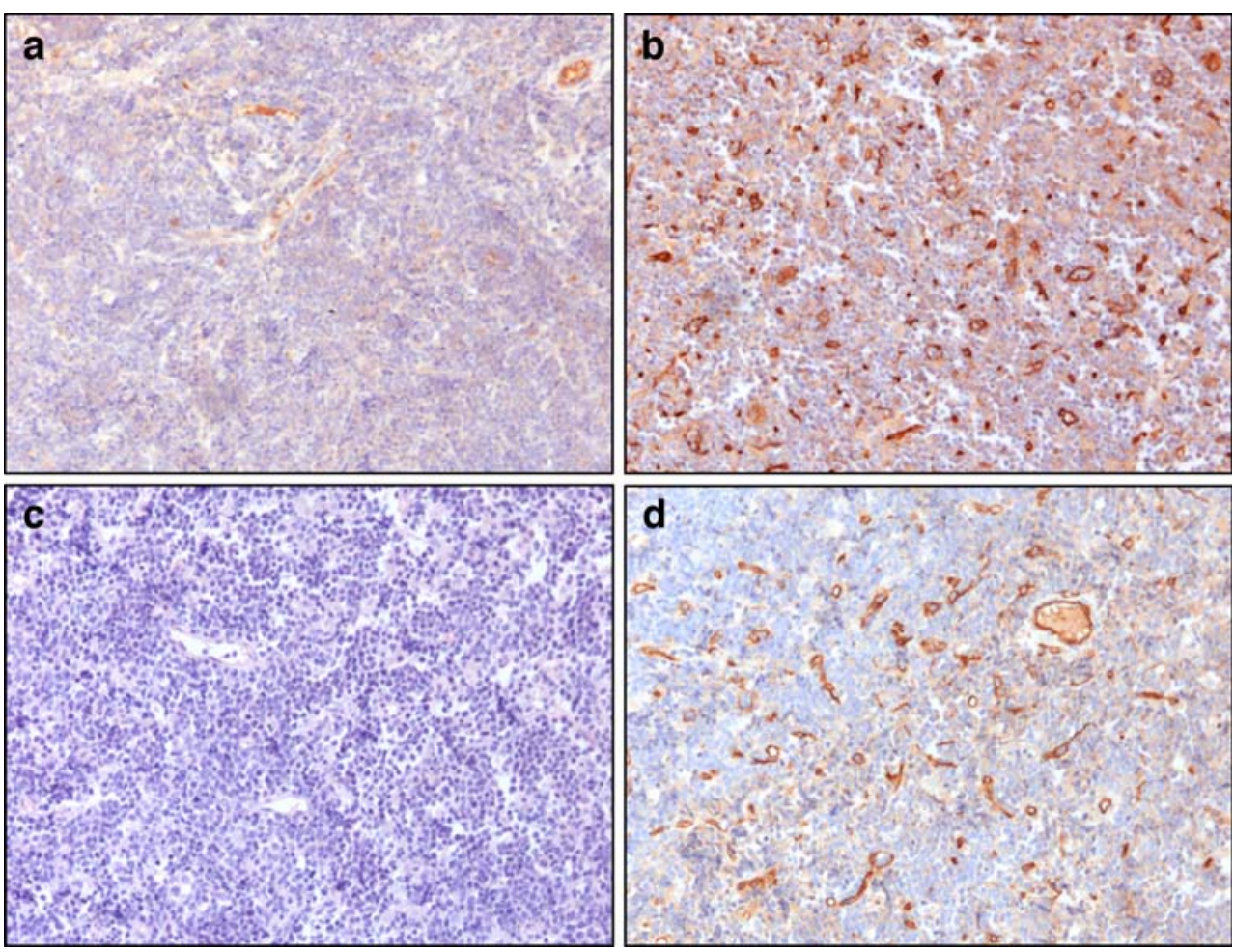

Previous studies have shown that Tat protein released by the infected cells in HIV-1 positive patients is a potential angiogenic factor and contributes to increase angiogenesis through binding to VEGFR-2 (Flk-1/KDR). Based on these facts, we analyzed the possibility that Tat may cooperate with VEGF in inducing angiogenesis. Our findings dem- 
Fig. 4 Microvessel counts and mean in both HIV-1 positive and HIV-1 negative BL and DLBCL tumors. In both BL and DLBCL, statistical significant values for microvessel counts were realized for the minimum (a; $p=0.042$ and $p=0.010$ ), maximum $(\mathbf{b} ; p=0.048$ and $p=$ $0.003)$, and median (c; $p=0.034$ and $p=0.005$ ), respectively. The mean for DLBCL was statistically significant but that of BL was on the borderline $(\mathbf{d} ; p=$ 0.003 and $p=0.051$ ) being attributed to the other angiogenic factors
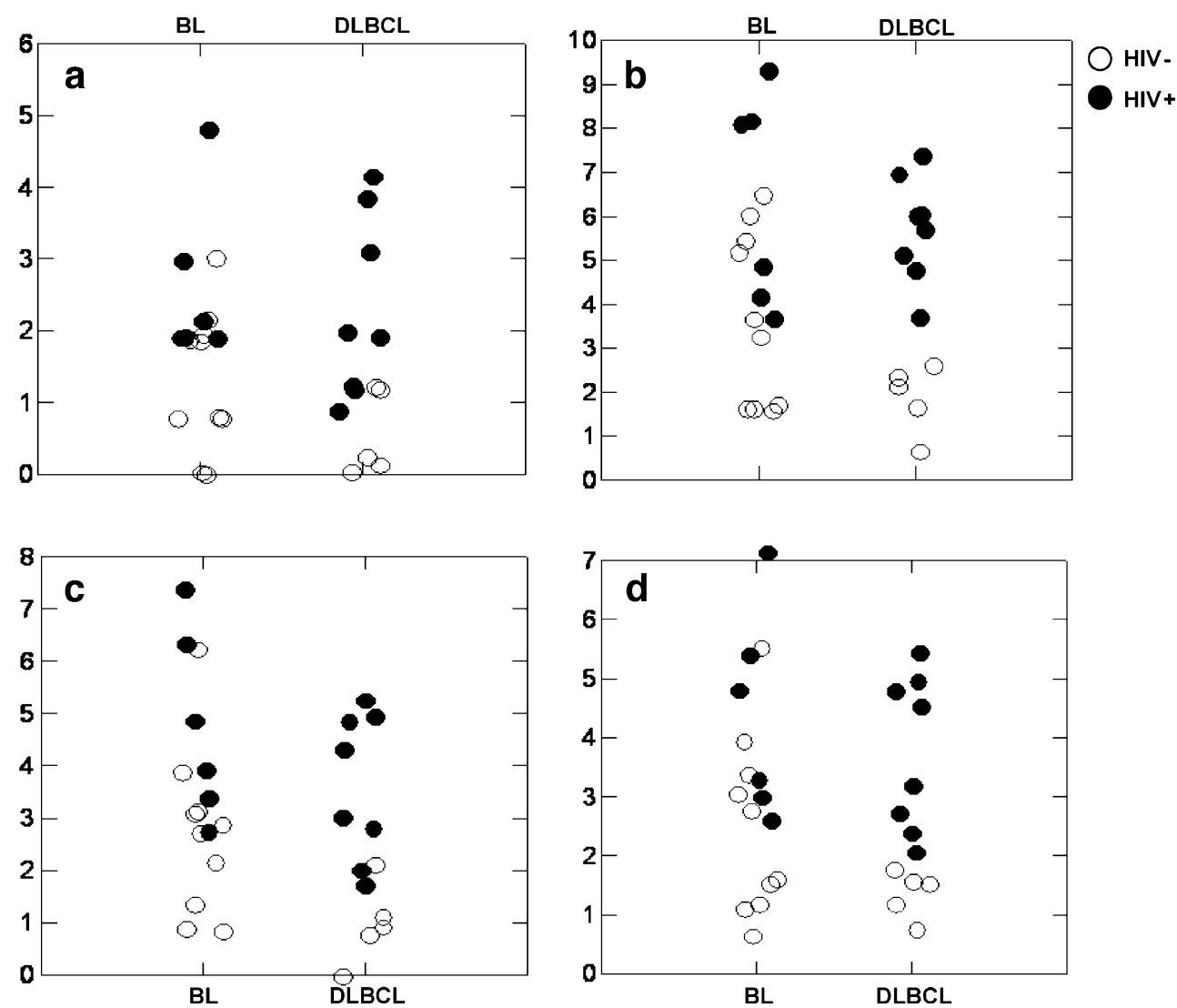

onstrated that Tat diminishes the promoter activity of VEGF promoter in vitro, suggesting that Tat may modulate the level of expression of VEGF. In the studied primary HIV-1 positive or HIV-1 negative diffuse large B-cell and Burkitt lymphomas, low expression of VEGF in HIV-1 positive as compared to the negative cases was observed, confirming the in vitro results. However, the microvessel density, assessed by CD34 expression, was intriguing being higher in HIV-1 positive as compared to the negative cases. This suggests that Tat plays a wider angiogenic role that is related to increase MVD. From our findings, it is possible to argue that Tat may increase angiogenesis through the direct binding to VEGFR2/KDR, thus inducing its downstream signaling rather than increasing angiogenesis through the enhancement of VEGF expression [30]. This may well explain why VEGF expression did not correlate with CD34 expression in the AIDS-related samples.

It has been demonstrated that endothelial cells express high levels of VEGFR1 (Flt-1) [31], a VEGF receptor with a higher affinity for VEGF as compared to KDR [32]. Although it has a higher affinity for VEGF, Flt-1 appears to be principally involved in the endothelial cell differentiation rather than in the vessel formation [33]. Through its higher affinity, Flt-1 could sequester partly or mostly of the VEGF produced. These observations suggest that the endogenous ligand for this receptor, VEGF, appears to be present at limiting the concentrations in vivo, whereas an exogenous ligand, such as Tat, would be free to bind and activate KDR. This, in part, could underlie the low VEGF expression in AIDS-associated lymphomas observed in our study cases. Other contributing angiogenic factors have, however, been elsewhere reported [34-36]. These results were not surprising given that HIV-1 Tat, which affects endothelial functions, has also been shown to downregulate endothelial differentiation-related factor-1, a novel gene product which could be downregulated when endothelial cells are induced to differentiate in vitro both at the RNA and protein levels [37].

While some studies reported no correlation between microvessel density and tumor grade [38, 39], the findings of this study suggest the need to design therapies targeting VEGF, VEGFRs, as well as Tat in the management approach in angiogenic phenotypes of AIDSassociated non-Hodgkin's lymphomas. Furthermore, it may be more interesting to dissect the molecular mechanisms underlying the activity of VEGF mimetic by Tat, given the functional interaction of receptors with dimeric ligand, molecules are known to dimerize receptors, followed by the activation of the intracellular kinase domain, of which no evidence so far has shown that Tat basic peptide is characterized [40, 41].

Although a much smaller binding epitope on the VEGF receptor surface is expected to be covered by the lowmonomeric (low-M $\mathrm{M}_{\mathrm{r}}$ ) Tat peptide mimetic of VEGF as 
compared to the highly complex dimeric VEGF, this study reveals that Tat mimetic of VEGF correlates well with the increased microvessel density. Therefore, future therapeutic designs targeting VEGF, VEGFRs, as well as Tat protein in the management of angioproliferative phenotypes of AIDSassociated non-Hodgkin's lymphomas may increase the chances of obtaining optimal therapy.

Acknowledgements This work was supported by an MIUR grant, Rome, Italy (L.L); MPS Foundation grant, Siena, Italy (L.L); and PAR grant, University of Siena, Siena-Italy (L.L).

\section{References}

1. Scheidegger P, Weiglhofer W, Suarez S, Console S, Waltenberger J, Pepper MS, Jaussi R, Ballmer-Hofer K (2001) Signalling properties of an HIV-encoded angiogenic peptide mimicking vascular endothelial growth factor activity. Biochem J 353:569-578

2. Bergers G, Benjamina LE (2003) Tumorigenesis and angiogenic switch. Nat Rev Cancer 3:401-410

3. Rosen LS (2002) Clinical experience with angiogenesis signalling inhibitors: focus on vascular endothelial growth factor (VEGF) blockers. Cancer Control 9(Suppl 2):36-44

4. McMahon G (2005) VEGF receptor signalling in tumour angiogenesis. Oncologist 5(Suppl 1):3-10

5. Dvorak HF (2002) Vascular permeability factor/vascular endothelial growth factor: a critical cytokine in tumour angiogenesis and potential target for diagnosis and therapy. J Clin Oncol 20:43684380

6. Warner-Schmidt JL, Duman RS (2007) VEGF is an essential mediator of the neurogenic and behavioural actions of antidepressants. Proc Natl Acad Sci U S A 104(11):4647-4652

7. Brkovic A, Sirois MG (2007) Vascular permeability induced by VEGF family members in vivo: role of endogenous PAF and NO synthesis. J Cell Biochem 100(3):727-737

8. Dezube BJ (2000) New therapies for the treatment of AIDSrelated Kaposi sarcoma. Curr Opin Oncol 12(5):445-449

9. Albini A, Benelli R, Presta M, Rusnati M, Ziche M, Rubartelli A, Paglialunga G, Bussolino F, Noonan D (1996) HIV-1 Tat protein is a heparin-binding angiogenic growth factor. Oncogene 12:289297

10. Morini M, Benelli R, Giunciuglio D, Carlone S, Arena G, Noonan DM, Albini A (2000) Kaposi's sarcoma cells of different etiologic origins respond to HIV-Tat through the Flk1/KDR (VEGFR-2): relevance in AIDS-KS pathology. Biochem Biophys Res Commun 273:267-271

11. Rusnati M, Presta M (2002) HIV-1 Tat protein and endothelium: from protein/cell interaction to AIDS-associated pathologies. Angiogenesis 5:141-151

12. Ensoli B, Gendelman R, Markham P, Fiorelli V, Colombini S, Raffeld M, Cafaro A, Chang HK, Brady JN, Gallo RC (1994) Synergy between basic fibroblast growth factor and HIV-1 Tat protein in induction of Kaposi's sarcoma. Nature (London) 371:674-680

13. Gallo RC (1996) The enigmas of Kaposi's sarcoma. Science 282:1837-1839

14. Lazzi S, Bellan C, De Falco G, Cinti C, Ferrari F, Nyongo A, Claudio PP, Tosi GM, Vatti R, Gloghini A, Carbone A, Giordano A, Leoncini L, Tosi P (2002) Expression of RB2/ p130 tumor-suppressor gene in AIDS-related non-Hodgkin's lymphomas: implications for disease pathogenesis. Human Pathol 33:723-731
15. Claudio PP, Stiegler P, Howard CM, Bellan C, Minimo C, Tosi GM, Rak J, Kovatich A, De Fazio P, Micheli P, Caputi M, Leoncini L, Kerbel R, Giordano A (2001) RB2/p130 gene enhanced expression down-regulates vascular endothelial growth factor expression and inhibits angiogenesis. Cancer Res 61:462-468

16. De Falco G, Bagella L, Claudio PP, De Luca A, Fu Y, Calabretta B, Sala A, Giordano A (2000) Physical interaction between CDK9 and $\mathrm{B}-\mathrm{Myb}$ results in suppression of B-Myb gene autoregulation. Oncogene 19:373-379

17. Ng IO, Poon RT, Lee JM, Fan ST, Ng M, Tso WK (2001) Micro vessel density, vascular endothelial growth factor and its receptors Flt-1 and Flk-1/KDR in hepatocellular carcinoma. Am J Clin Pathol 116(6):838-845

18. Takahashi Y, Kitadai Y, Bucana CD, Cleary KR, Ellis LM (1995) Expression of vascular endothelial growth factor and its receptor, KDR, correlates with vascularity, metastasis, and proliferation of human colon cancer. Cancer Res 55:39643968

19. Vermeulen K, Van Bockstaele DR, Berneman ZN (2003) The cell cycle: a review of regulation, deregulation and therapeutic targets in cancer. Cell Prolif 36:131-149

20. Gala JL, Vandenbroucke AT, Vandercam B, Pirnay JP, Delferrière N, Burtonboy G (1997) HIV-1 detection by nested PCR and viral culture in fresh or cryopreserved post-mortem skin: potential implications for skin handling and allografting. J Clin Pathol 50 (6):481-484

21. Barillari G, Ensoli B (2002) Angiogenic effects of extra cellular human immunodeficiency virus type 1 Tat protein and its role in the pathogenesis of AIDS-associated Kaposi's sarcoma. Clin Microbiol Rev 15:310-326

22. Gratzinger D, Zhao S, Marinelli RJ, Kapp AV, Tibshirani RJ, Hammer AS, Hamilton-Dutoit S, Natkunam Y (2007) Micro vessel density and expression of vascular endothelial growth factor and its receptors in diffuse large B-cell lymphoma subtypes. Am J Pathol 170(4):1362-1369

23. Reigstad LJ, Varhaug JE, Lillehaug JR (2005) Structural and functional specificities of PDGF-C and PDGF-D, the novel members of the platelet-derived growth factors family. FEBS $\mathrm{J}$ 272(22):5723-5741

24. Ruch C, Skiniotis G, Steinmetz MO, Walz T, Ballmer-Hofer K (2007) Structure of a VEGF-VEGF receptor complex determined by electron microscopy. Nat Struct Mol Biol 14(3):249-250

25. Santos SC, Miguel C, Domingues I, Calado A, Zhu Z, Wu Y, Dias $S$ (2007) VEGF and VEGFR-2 (KDR) internalization is required for endothelial recovery during wound healing. Exp Cell Res 313 (8):1561-1574

26. Yamazaki Y, Nakano Y, Imamura T, Morita T (2007) Augmentation of vascular permeability of VEGF is enhanced by KDR-binding proteins. Biochem Biophys Res Commun 355 (3):693-699

27. Fearon U, Griosios K, Fraser A, Reece R, Emery P, Jones PF, Veale DJ (2003) Angiopoietins, growth factors, and vascular morphology in early arthritis. J Rheumatol 30(2):260-268

28. Waltenberger J (1997) Modulation of growth factor action: implications for the treatment of cardiovascular diseases. Circulation 96(11):4083-4094

29. Aoki Y, Tosato G (2003) Targeted inhibition of angiogenic factors in AIDS-related disorders. Curr Drug Targets Infect Disord 3 (2):115-128

30. Albini A, Soldi R, Giunciuglio D, Giraudo E, Benelli R, Primo L, Noonan D, Salio M, Camussi G, Rockl W, Bussolino F (1996) The angiogenesis induced by HIV-1 tat protein is mediated by the Flk-1/KDR receptor on vascular endothelial cells. Nat Med 2 (12):1371-1375

31. Brown LF, Tognazzi K, Dvorak HF, Harrist TJ (1996) Strong expression of kinase insert domain-containing receptor, a vascular 
permeability factor/vascular endothelial growth factor receptor in AIDS-associated Kaposi's sarcoma and cutaneous angiosarcoma. Am J Pathol 148:1065-1074

32. Dvorak HF, Detmar M, Claffey KP, Nagy JA, van De Water L, Senger DR (1995) Vascular permeability factor/vascular endothelial growth factor: an important mediator of angiogenesis in malignancy and inflammation. Int Arch Allergy Immunol 107:233-235

33. Fong GH, Rossant J, Gertsenstein M, Breitman ML (1995) Role of the Flt-1 receptor tyrosine kinase in regulating the assembly of vascular endothelium. Nature 376:66-70

34. Bardelli M, Leucci E, Schurfeld K, Bellan C, Passiatore G, Rocchigiani M, Bartolommei S, Orlandini M, Zagursky J, Lazzi S, De Falco G, Tosi P, Oliviero S, Leoncini L (2007) VEGF-D is expressed in activated lymphoid cells and in tumors of hematopoietic and lymphoid tissues. Leuk Lymphoma 48 (10):2014-2021

35. Pritchard-Jones RO, Dunn DB, Qiu Y, Varey AH, Orlando A, Rigby H, Harper SJ, Bates DO (2007) Expression of VEGF (xxx) $\mathrm{b}$, the inhibitory isoforms of VEGF, in malignant melanoma. $\mathrm{Br} \mathbf{J}$ Cancer 97(2):223-230

36. Petersen W, Pufe T, Unterhauser F, Zantop T, Mentlein R, Weiler A (2003) The splice variants 120 and 164 of the angiogenic peptide vascular endothelial cell growth factor (VEGF) are expressed during Achilles tendon healing. Arch Orthop Trauma Surg 123(9):475-480

37. Dragoni I, Mariotti M, Consalez GG, Soria MR, Maier JA (1998) EDF-1, a novel gene product down-regulated in human endothelial cell differentiation. J Biol Chem 273(47):3111931124

38. Mazur G, Wróbel T, Dziegiel P, Jeleń M, Kuliczkowski K, Zabel M (2004) Angiogenesis measured by expression of CD34 antigen in lymph nodes of patients with non-Hodgkin's lymphoma. Folia Histochem Cytobiol 42(4):241-243

39. Zagury D, Lachgar A, Chams V et al (1998) Interferon alpha and Tat involvement in the immunosupression of uninfected $\mathrm{T}$ cells and $\mathrm{C}-\mathrm{C}$ chemokine decline in AIDS. Proc Natl Acad Sci U S A 95:3851-3856

40. Ranieri G, Patruno R, Ruggieri E, Montemurro S, Valerio P, Ribatti D (2006) Vascular endothelial growth factor (VEGF) as a target of bevacizumab in cancer: from the biology to the clinic. Curr Med Chem 13(16):1845-1857

41. Dell'Eva R, Pfeffer U, Vené R, Anfosso L, Forlani A, Albini A, Efferth T (2004) Inhibition of angiogenesis in vivo and growth of Kaposi's sarcoma xenograft tumors by the anti-malarial artesunate. Biochem Pharmacol 68(12):2359-2366 